\title{
A Morphometric Study of Adult Human Sterna from the Galloway Osteological Collection
}

\author{
Gonzaga Gonza Kirum ${ }^{\circledast 1}$, John Kukiriza ${ }^{\circledR 2}$, Gerald Tumusiime ${ }^{\circledR 3}$ \\ ${ }^{1}$ Lecturer, Department of Anatomy, School of Biomedical Sciences, College of Health Sciences, Makerere University, Kampala, Uganda, ${ }^{2}$ Lecturer, Department of \\ Anatomy, Earnest Cook Ultrasound Research and Education Institute (ECUREI), Kampala, Uganda, ${ }^{3}$ Senior Lecturer, Department of Anatomy, School of Medicine, \\ Uganda Christian University (UCU), Mukono, Uganda.
}

\section{Abstract}

Background: Morphometric knowledge of the sternum is of great significance in cardiac surgery as variations in sternal dimensions have been considered a risk factor for translocation of suture material during median sternotomy, leading to poor outcomes. Fatalities attributed to subnormal sternal thickness have also been reported during sternal biopsies. Fractures of the sternum secondary to chest injury or cardio-pulmonary resuscitation may also be influenced by sternal thickness. Elongated xiphoid process can be mistaken for an epigastric mass which can be painful on palpation. Morphometric studies of African sterna are rare. The objective is to the study sought to describe the morphometry of adult sterna from the Galloway bone collection, Makerere University, Kampala, Uganda. Subjects and Methods: This study employed a descriptive cross sectional design to collect and analyze quantitative data. Eighty five dry adult sterna (75 males and 10 females) were examined at the Department of Human Anatomy, Makerere University. Data analysis at univariate and bivariate levels were performed using SPSS version 21.0 statistical software. Results:A significant difference in the average length of the mesosternum was found between males at $94.6 \mathrm{~mm}$ (SD 11.2) and females at $82.2 \mathrm{~mm}$ (SD 15.2) ( $\mathrm{P}=0.002)$. Two cases (9.5\%) presented with elongated xiphoid process and one (1.2\%) with subnormal mesosternal thickness. Conclusions: Our study highlights the importance of knowledge of the sternal morphometry in sex identification, physical examination, sternal puncture and other thoracic procedures, calling for increased awareness of the findings.

Keywords: Morphometry, Sternum, Median Sternotomy, Sternal Puncture, Sternal Fracture

Corresponding Author: Gonzaga Gonza Kirum, Lecturer, Department of Anatomy, School of Biomedical Sciences, College of Health Sciences, Makerere University, Kampala, Uganda.

E-mail: g_kirum@yahoo.com

Received: 30 August 2020

Revised: 15 October 2020

Accepted: 25 October 2020

Published: 22 December 2020

\section{Introduction}

Morphometric knowledge of the sternum is of great significance in cardiac surgery, considering the fact that midline splitting of the sternum is the most commonly used method to access mediastinal structures. ${ }^{[1]}$ During this operation, the sternum is split into halves from the suprasternal notch to the caudal end of the xiphoid process. Variations in the dimensions of the sternum has been reported as a risk factor for translocation of suture material across the sternum during this surgical intervention, ${ }^{[2,3]}$ leading to poor outcomes. ${ }^{[1]}$ The sternum is also commonly punctured during bone marrow aspiration due to its broadness and superficial location. The thickness of the sternum is an important consideration in this procedure as fatalities have been previously documented. ${ }^{[4,5]}$ The thickness may also influence occurrence of fractures of the sternum during minor injury to the anterior thoracic wall or cardio-pulmonary resuscitation. ${ }^{[6-9]}$ These fractures not only increase the risk of damage to middle mediastinal structures, but may also compromise ventilation and complicate recovery. An elongated xiphoid process can be mistaken for an epigastric mass which can be painful on palpation. ${ }^{[10]}$

There are few previous reports on the morphometry of African sterna. A recent Kenyan study found that $16.0 \%$ of cases had manubrial thickness less than $10 \mathrm{~mm} .{ }^{[11]}$ It also reported $8.6 \%$ cases in which the body thickness was less than 8 $\mathrm{mm}$. In the same study, the mean manubrial thickness was $12.1 \pm 1.3 \mathrm{~mm}$ in males and $10.4 \pm 1.2 \mathrm{~mm}$ in females $(\mathrm{P}=0.163)$; while mesosternal thickness measured $10.2 \pm 1.2$ $\mathrm{mm}$ and $8.3 \pm 1.1 \mathrm{~mm}$ in males and females respectively $(\mathrm{P}=0.159)$. The authors concluded that the sterna of Kenyan origin varied in morphometry from those reported elsewhere and that the variations may present challenges during median sternotomy and may make the bones prone to fractures. 
However, to our knowledge, no study has reported on sternal morphometry in Uganda and therefore the aforementioned risk may be overlooked by unsuspecting clinicians, with serious consequences to the patients.

This study therefore set out to describe the morphometry of dry adult sterna from the Galloway bone collection at the Department of Human Anatomy, Makerere University, Kampala, Uganda.

\section{Subjects and Methods}

The study population was composed of adult human sterna derived from the Galloway osteological collection at the Department of Human Anatomy, Makerere University, Uganda. They were obtained from cadaveric specimens by making bilateral longitudinal incisions through the sternocostal articulations and the sterna removed as complete bones. These sterna were then soaked in a solution of $10 \%$ formalin for two months and the remaining soft tissues carefully removed from their surfaces. All specimens aged 18-45 years with intact manubriosternal joint were included in the study. Bones that were broken, and without sex and age record were excluded. Only 100 sterna were available in the study institution at the time of data collection, and all were included in the study, in accordance with the postulation of Gay and Airasian. ${ }^{[12]}$ The aforementioned author suggests that for limited populations of 100 or less, $100 \%$ of that population should be included in the study. Only 85 sterna (75 males and 10 females) were however studied as some either did not meet the inclusion criteria or fulfilled the exclusion criteria. For this study, the archived sterna were retrieved and scrutinized for completeness and fulfillment of the inclusion criteria. The demographics (age and sex) of the specimens were abstracted from the bone catalogue present in the Gross Anatomy Laboratory.

With the help of a Draper Expert 52427 digital vernier caliper (Draper Tools LTD, Hampshire, UK: accuracy $\pm 0.01 \mathrm{~mm}$ ), Figure 1c, the length, width and thickness of the manubrium and mesosternum as well as xiphoidal length were determined. Manubrium length was determined from the center of the suprasternal notch to the center of the sternal angle, body length from sternal angle to sternoxiphoid symphysis while xiphoidal length from sternoxiphoid symphysis to the inferior xiphoidal end, ${ }^{[13,14]}$ [Figure 1a]. The manubrial width and thickness was measured just below the clavicular notches and just above the sternal angle, ${ }^{[11,13]}$ [Figure 1b], and an average obtained. The width and thickness of the mesosternum, on the other hand, were determined at the second, third, fourth, fifth and sixth intercostal notches, ${ }^{[11,13]}$ [Figure 1b], and averages computed. Measurements were separately done by two independent persons at two different sittings and means of their readings were calculated. Any mesosternum less than
$5 \mathrm{~mm}$ thick, ${ }^{[4]}$ and any manubrial length greater than 58.8 $\mathrm{mm}$ in males and $56.9 \mathrm{~mm}$ in females were respectively taken as subnormal and abnormally long. ${ }^{[13]}$ Elongated xiphoid process, on the other hand, was defined as one longer than 40 $\mathrm{mm} .{ }^{[10]}$ Representative sterna were photographed using a 20.1 megapixel Coolpix S2900 digital camera (Nikon Corporation, Tokyo, Japan). Data was analyzed using SPSS 21.0 statistical software (IBM, Armonk, NY, USA), where averages and standard deviations of the measurements were computed from descriptive statistics. Cohen's kappa statistics (k) was used to determine the level of agreement in the measurements of the two independent observers. The relationship between age and the measured parameters were determined using Pearson correlation. Independent students' t-test was used to compute differences across sex. For all analyses, a P-value of $\leq$ 0.05 was considered significant. Ethical approval (approval number SBS 308) was sought from the Makerere University School of Biomedical Sciences-Higher Degrees Research and Ethics Committee (MakSBS-HDREC) before starting data collection.

\section{Results}

The two independent observers agreed strongly in the readings of the manubrium length $(\mathrm{k}=1.000, \mathrm{P}<0.001)$, manubrium breadth $(\mathrm{k}=0.823, \mathrm{P}<0.001)$, body length $(\mathrm{k}=0.929, \mathrm{P}<0.001)$, body breadth $(\mathrm{k}=0.976, \mathrm{P}<0.001)$ and xiphoidal length $(\mathrm{k}=1.000, \mathrm{P}<0.001)$. They also agreed mildly $(\mathrm{k}=0.248$, $\mathrm{P}=0.019)$ and moderately $(\mathrm{k}=0.602, \mathrm{P}<0.001)$ in their respective measurements of the manubrial and mesosternal thickness. More than three quarters of the specimens $70(82.4 \%)$ were between $21-40$ years old and were males 75 (88.2\%). The average age was 32 years (SD 6.9) with a standard error of the mean as 0.7. Manubrium thickness measured less than $10 \mathrm{~mm}$ in eight $(9.4 \%)$ specimens while in $26(30.6 \%)$ cases, the sternal body was less than $8 \mathrm{~mm}$ thick. Only one (1.2\%) case of subnormal mesosternal thickness was found. A case of an abnormally long manubrium $1(1.2 \%)$ was also seen. Of the $21(24.7 \%)$ specimens with xiphoid process, two (9.5\%) presented with elongated xiphoid process. Pearson correlation established no statistically significant linear relationship between age and the measured parameters ( $\mathrm{P}>0.05$ for all). The studied parameters are summarized in Table 1.

\section{Discussion}

We described the morphometry of adult human African sterna from Uganda. We found a significant difference between male and female mesosternal length. The male sternal body was significantly longer $(\mathrm{P}<0.05)$ than the female [Table 1 ], consistent with previous reports. ${ }^{[15-19]}$ The aforementioned authors also demonstrated that mesosternal length can be used to accurately discriminate sex. This finding can therefore 
Table 1: Sternal measurements

\begin{tabular}{|c|c|c|c|c|c|}
\hline & \multirow{2}{*}{$\begin{array}{l}\text { Male } \\
\text { Mean (SD) }\end{array}$} & \multicolumn{3}{|l|}{ Female } \\
\hline & Sternal segment Parameter (mm) & & Mean (SD) & $\mathbf{t}$ & P-value \\
\hline \multirow[t]{4}{*}{ Manubrium } & Length & $46.0(5.0)$ & $43.9(3.8)$ & 1.3 & 0.208 \\
\hline & Width & $39.8(6.0)$ & $38.2(6.8)$ & 0.8 & 0.427 \\
\hline & Thickness & $12.1(1.8)$ & $12.1(1.8)$ & -0.1 & 0.912 \\
\hline & $\begin{array}{l}\text { Manubrium Index } \\
\text { (MI) }\end{array}$ & $0.9(0.1)$ & $0.9(0.2)$ & -0.13 & 0.900 \\
\hline \multirow[t]{4}{*}{ Sternal body } & Length & $94.6(11.2)$ & $82.2(15.2)$ & 3.2 & 0.002 \\
\hline & Width & $28.3(4.7)$ & $26.7(5.2)$ & 1.0 & 0.324 \\
\hline & Thickness & $8.5(1.0)$ & $8.7(0.5)$ & -0.7 & 0.472 \\
\hline & $\begin{array}{ll}\text { Sternal } & \text { Body } \\
\text { Index (BI) } & \end{array}$ & $0.3(0.1)$ & $0.3(0.1)$ & -1.26 & 0.129 \\
\hline Xiphoid process & Length & $27.3(7.9)$ & $26.2(4.4)$ & 0.2 & 0.845 \\
\hline
\end{tabular}

MI = Manubrium width/Manubrium length; $\mathbf{B I}=$ Sternal body width/Sternal body length

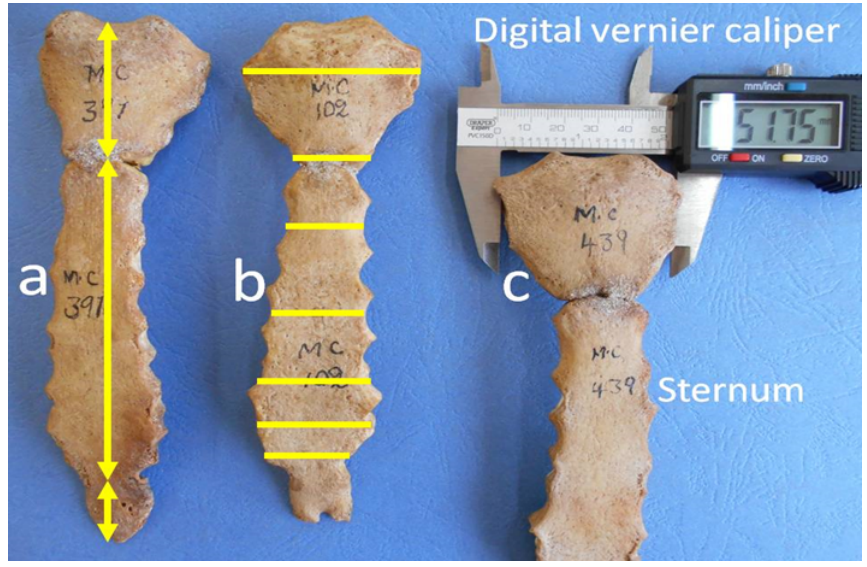

Figure 1: Photograph showing the materials and landmarks used in the study. a -Landmarks used to measure the segmental lengths of the sternum (Adopted from previous work). $\mathbf{b}$-Landmarks used to measure the segmental breadth and thickness of the sternum (Adopted from previous work). c -Materials used in the study (Adopted from previous work). $[11,13,14]$

be useful in forensincs for accurate sex estimation. To date, the pelvis and the skull are still commonly used in sex identification because of their high osteometric sex discrimination accuracy. ${ }^{[16]}$ However, in the event that these skeletal components are unavailable or damaged, the sternum can be a useful substitute. The rest of the parameters studied showed morphometric variations across gender, but these were not statistically significant [Table 1].

Nearly a tenth of the manubrium $8(9.4 \%)$ and a third of the mesosternum $26(30.6 \%)$ were less than $10 \mathrm{~mm}$ and 8 $\mathrm{mm}$ thick respectively. This finding conflicts that from a Kenyan study, ${ }^{[11]}$ which reported $16.0 \%$ and $8.6 \%$ cases of manubrial and mesosternal thickness as under $10 \mathrm{~mm}$ and $8 \mathrm{~mm}$ respectively. The disparity may partly be attributable to differences in Biological growth and development of the two populations and calls for utilization of population-specific statistics in forensic analyses, sternal punctures and cardiopulmonary resuscitations. The present study also found a single case $(1.2 \%)$ of a male sternal body measuring $4.49 \mathrm{~mm}$ thick. According to Bhootra, the normal male mesosternum is usually thicker than $5 \mathrm{~mm} .{ }^{[4]}$ A thickness of $4.49 \mathrm{~mm}$ is therefore subnormal. Unintended fatalities during sternal biopsy have been previously reported with such subnormal thicknesses of the mesosternum. ${ }^{[4,5]}$ This is because the needle is forced past this thickness, injuring mediastinal structures. Clinicians should be aware of the normal thickness of the mesosternum and take due caution during sternal puncture so as to prevent these iatrogenic injuries and possible deaths. Thin mesosterna are also prone to fractures during minor injury to the anterior thoracic wall, [6] artificial respiration (cardiopulmonary resuscitation) or cardiac massage. ${ }^{[-9]}$ Fractures sustained during these procedures may lead to fatal heart and great vessel injuries, warranting caution.

One case $(1.2 \%)$ of an abnormally long manubrium and two cases $(9.5 \%)$ of elongated xiphoid process were also identified in the present study. The single case of abnormally long manubrium shifted the angle of Louis from the second costal cartilage (normal location) to the third costal cartilage. In this case, the sternal angle was $6.2 \mathrm{~cm}$ inferior to the jugular notch. This anomaly may arise from fusion of accessory ossification centers within the manubrium and should be suspected if the sternal angle is more than $5 \mathrm{~cm}$ inferior to the jugular notch. ${ }^{[20-22]}$ The anomaly may shift the angle of Louis from 
its normal placement at the second costal cartilage to the third costal cartilage, ${ }^{[22]}$ consistent with the findings of the present study. Although these findings were rare, they are of great clinical importance. The angle of Louis is an important guide to the accurate counting of the ribs. In the living, this angle is visible and palpable. The second costal cartilage can be easily palpated at either side of the angle; the ribs must be counted down from this angle as one of the certain guides to their numerical identification. ${ }^{[23]}$ Misplaced sternal angles secondary to abnormal lengths of the manubrium may therefore result in inaccurate rib counting. This may complicate invasive thoracic procedures like thoracocentesis by misguiding the clinician on which intercostal space to insert the needle. ${ }^{[24]}$ Consequently, there may be severe iatrogenic injury to mediastinal structures and the success of the aforementioned procedures may not be guaranteed. An elongated xiphoid process, on the other hand, can be mistaken for an epigastric mass on palpation and can be painful. Clinicians should be aware of it during physical examination to avoid misdiagnosis. ${ }^{[10]}$

The small sample size of our study may limit the generalizability of our findings. Besides, the smaller number of female specimens compared to males, may have influenced the findings with regard to sex differences. The findings may not provide a good nationwide picture of the Ugandan population since this study was based within an institution. Selection bias may also be introduced in the study because a non-probability sampling technique was used due to limited specimens in the study institution.

\section{Conclusions}

Our study highlights the importance of knowledge of the sternal morphometry in sex identification, physical examination, sternal puncture and other thoracic procedures, calling for increased awareness of the findings.

\section{Acknowledgements}

We extend our gratitude to Mr. Mesach Kange, the Anatomy Departmental Laboratory Technician for his assistance with retrieval of the archived specimens, and to the African Development Bank-Higher Education Science and Technology (AfDB-HEST) Program through the Makerere University Planning Department for funding this study.

\section{References}

1. Losanoff JE, Jones JW, Richman BW. Primary closure of median sternotomy: techniques and principles. Cardiovasc Surg. 2002;10(2):102-110. Available from: https://doi.org/10. 1016/s0967-2109(01)00128-4.
2. Osada T, Kawachi K, Fujikawa T. A new method for closure of median sternotomy: application of a steppler system. Japan J Thorac Surg. 1990;43:973-976.

3. Shafir R, Weiss J, Herman O, Cohen N, Stern D, Igra Y. Faulty sternotomy and complications after median sternotomy. $\mathrm{J}$ Thorac Cardiovasc Surg. 1988;96(2):310-313. Available from: https://dx.doi.org/10.1016/s0022-5223(19)35277-8.

4. Bhootra BL. Fatality following a sternal bone marrow aspiration procedure: a case report. Med Sci Law. 2004;44(2):170172. Available from: https://doi.org/10.1258/rsmmsl.44.2.170.

5. Inoue $\mathrm{H}$. Risk factors concerning sternal bone marrow aspiration and patient safety in Japan. Internal Med. 2010;49(12):1089-95. Available from: https://doi.org/10. 2169/internalmedicine.49.3243.

6. Waele JJD, Calle PAA, Blondeel L, Vermassen FEG. Blunt Cardiac Injury in Patients with Isolated Sternal Fractures: the Importance of Fracture Grading. Eur J Trauma. 2002;28(3):178-182. Available from: https://dx.doi.org/10. 1007/s00068-002-1136-9.

7. Baubin M, Rabl W, Pfeiffer KP, Benzer A, Gilly H. Chest injuries after active compression-decompression cardiopulmonary resuscitation (ACD-CPR) in cadavers. Resuscitation. 1999;43(1):9-15. Available from: https://dx.doi.org/10.1016/ s0300-9572(99)00110-0.

8. Lederer W, Mair D, Rabl W, Baubin M. Frequency of rib and sternum fractures associated with out-of-hospital cardiopulmonary resuscitation is underestimated by conventional chest X-ray. Resuscitation. 2004;60(2):157-162. Available from: https://dx.doi.org/10.1016/j.resuscitation.2003.10.003.

9. Rabt W, Broinger G, Scheithauer R, Baubin M. Serious complications from active compression-decompression cardiopulmonary resuscitation. Int J Legal Med. 1996;109(2):84-89. Available from: https://dx.doi.org/10.1007/bf01355522.

10. Duraikannu C, Noronha O, Sundarrajan P. MDCT evaluation of sternal variations: Pictorial essay. Indian J Radiol Imaging. 2016;26(2):185-185. Available from: https://dx.doi.org/10. 4103/0971-3026.184407.

11. El-Busaidy H, Kaisha W, Hassanali J, Hassan H, Ogeng'o J, Munene J. Anatomical features of the sternum in a Kenyan population. Anat J Afr. 2014;3(1):228-232.

12. Gay LR, Airasian P. Educational Research Competencies for Analysis and Application. NJ: Merrill, Prentice Hall; 2003.

13. Selthofer R, Nikolić V, Mrcela T, Radić R, Leksan I, Rudez I. Morphometric analysis of the sternum. Coll Antropol. 2006;30(1):43-47.

14. Kirum GG, Munabi IG, Kukiriza J, Tumusiime G, Kange M, Ibingira $\mathrm{C}$, et al. Anatomical variations of the sternal angle and anomalies of adult human sterna from the Galloway osteological collection at Makerere University Anatomy Department. Folia Morphologica. 2017;76(4):689-694. Available from: https://dx.doi.org/10.5603/fm.a2017.0026.

15. Ekizoglu O, Hocaoglu E, Inci E, Bilgili MG, Solmaz D, Erdil I, et al. Sex Estimation From Sternal Measurements Using Multidetector Computed Tomography. Medicine. 2014;93(27):e240-e240. Available from: https://dx.doi.org/10. 1097/md.0000000000000240.

16. Torimitsu S, Makino Y, Saitoh H, Sakuma A, Ishii N, Inokuchi G, et al. Estimation of sex in Japanese cadavers based on sternal measurements using multidetector computed 
tomography. Legal Medicine. 2015;17(4):226-231. Available from: https://dx.doi.org/10.1016/j.legalmed.2015.01.003.

17. Chandrakanth HV, Kanchan T, Krishan K. Osteometric analysis for sexing of modern sternum - An autopsy study from South India. Legal Medicine. 2014;16:350-356. Available from: https://dx.doi.org/10.1016/j.legalmed.2014.07.007.

18. Bruce JS. Utility of the sternum to estimate sex and age. Boston; 2014.

19. Yonguc GN, Kurtulus A, Bayazit O, Adiguzel E, Unal I, Demir $\mathrm{S}$, et al. Estimation of stature and sex from sternal lengths: an autopsy study. Anat Sci Int. 2015;90(2):89-96. Available from: https://dx.doi.org/10.1007/s12565-014-0235-0.

20. Currarino G, Swanson GE. A Developmental Variant of Ossification of the Manubrium Sterni in Mongolism. Radiol. 1964;82(5):916-916. Available from: https://dx.doi.org/10. 1148/82.5.916.

21. Horns JW, O\&apos;loughlin, Bj. Multiple Manubrial Ossification Centers in Mongolism. Am J Roentgenol Radium Ther Nucl Med. 1965;93:395-398.

22. Moore KL; 2013.
23. Sinnatamby CS, Thorax. Last's Anatomy, Regional and Applied. Livingstone PC, editor. Elsevier Limited; 1999.

24. Williams P, Lawrence H, Martin M, Patricia C, D M, Anatomy JEG. 39th ed London: Churchill Livingstone TT, editor; 2004.

Copyright: (C) the author(s), 2020. It is an open-access article distributed under the terms of the Creative Commons Attribution License (CC BY 4.0), which permits authors to retain ownership of the copyright for their content, and allow anyone to download, reuse, reprint, modify, distribute and/or copy the content as long as the original authors and source are cited.

How to cite this article: Kirum GG, Kukiriza J, Tumusiime G. A Morphometric Study of Adult Human Sterna from the Galloway Osteological Collection. Acad. Anat. Int. 2020;6(2):45-49.

DOI: dx.doi.org/10.21276/aanat.2020.6.2.9

Source of Support: African Development Bank-Higher Education Science and Technology (AfDB-HEST) Program through the Makerere University Planning Department., Conflict of Interest: None declared. 